\title{
Review of the Hydrogeological Controls on Coalbed Methane (CBM) and Development Trends
}

\author{
Bo Wang, ${ }^{1,2}$ Dangliang Wang $\mathbb{D}^{3}{ }^{3}$ Wenjie Cao, ${ }^{4}$ Guofu Li, ${ }^{1}$ Wei Hou, ${ }^{5,6}$ Xinrui Cui, \\ Tao Hou, ${ }^{7}$ and Mingjian $\mathrm{Shi}^{2}$ \\ ${ }^{1}$ State Key Laboratory of Coal and Coalbed Methane Co-mining, Shanxi Jincheng Anthracite Mining Group Co., Ltd., \\ Jincheng 048000, China \\ ${ }^{2}$ Information Institute of the Ministry of Emergency Management of PRC, Beijing 100029, China \\ ${ }^{3}$ School of Geoscience \& Surveying Engineering, China University of Mining \& Technology (Xuzhou), Xuzhou 221116, China \\ ${ }^{4}$ School of Geoscience \& Surveying Engineering, China University of Mining \& Technology (Beijing), Beijing 100083, China \\ ${ }^{5}$ PetroChina Coalbed Methane Company Limited, Beijing 100083, China \\ ${ }^{6}$ Zhonglian CBM State Engineering Research Center Co., Ltd., Beijing 100095, China \\ ${ }^{7}$ PetroChina Huabei Oilfield Company, Renqiu 062550, China
}

Correspondence should be addressed to Dangliang Wang; wangdangliang@cumt.edu.cn

Received 8 April 2021; Revised 10 September 2021; Accepted 8 October 2021; Published 22 November 2021

Academic Editor: Chris Harris

Copyright (c) 2021 Bo Wang et al. This is an open access article distributed under the Creative Commons Attribution License, which permits unrestricted use, distribution, and reproduction in any medium, provided the original work is properly cited.

\begin{abstract}
Hydrogeological conditions can control the generation, preservation, enrichment, and production of coalbed methane (CBM) in the field; however, research on these impacts is insufficient, resulting in the limitation of the development of coalbed methane. This paper summarizes the current research status and development trends of the effect of hydrogeology on CBM using methods such as mathematical statistics, literature analysis, well logging, and hydrochemical analysis. The results indicate that it is beneficial for the generation of secondary biogenic gases in low-rank coal seams under the situations like active hydrodynamic conditions with a salinity less than $1000 \mathrm{mg} / \mathrm{L}$, a $\mathrm{pH}$ range from 5.9 to 8.8 , or a range of oxidation-reduction potential from $-540 \mathrm{mV}$ to $-590 \mathrm{mV}$. The abnormally high temperature due to the magmatichydrothermal fluids accelerates the metamorphism of coal rocks, leading to the promotion of the generation of thermogenic gases. When the coalbed structural conditions of one area are similar to the depositional conditions in that area, the CBM is accumulated if the conditions of that area meet the following criteria: the water type is $\mathrm{NaHCO}_{3}$, the salinity is greater than $1500 \mathrm{mg} / \mathrm{L}$, the desulfurization coefficient is less than 1 , and the sodium-chloride coefficient is less than 10. The stable isotope analysis of CBM well-produced water shows that the $\delta \mathrm{D}$ values in the groundwater shift to the left of the global meteoric water line, indicating that the produced water comes from atmospheric precipitation. In the CBM enrichment zone, the area with a relatively high salinity and a low sodium-chloride coefficient is the high-production area. Based on our study, three high CBM-production patterns are summarized: coalbed structure-hydraulic trapping, fold limb-fracture development, and syncline core-water stagnation. Additionally, four development trends of the control of hydrogeology on CBM are proposed: transformation from qualitative evaluation to quantitative evaluation, from a singular evaluation standard to multiple evaluation standards, from static evaluation to dynamic evaluation, and from pure theoretical research to theoretical guidance on production practices.
\end{abstract}

\section{Introduction}

Hydrogeological conditions have impacts on the processes of the formation, enrichment, accumulation, and production of $\mathrm{CBM}$ in coalbed. Groundwater is not only the medium for the generation of CBM $[1,2]$ but also the driving force for the migration of $\mathrm{CBM}$ and the carrier of the production of CBM [3-5]. After nearly 20 years of explorations and studies on CBM, abundant theoretical findings about the role of hydrogeological conditions in gas controlling are achieved, 
which effectively guides the selection of CBM enrichment areas. However, few studies on the quantitative evaluation about the hydrogeology in the enrichment areas and its effect on high CBM production are conducted. Therefore, on the basis of reviewing the current research on the gas controlling effect of hydrogeology around the world, this paper analyzes the existing scientific problems and explores the development trends of gas control research with the expectation to guide the efficient extraction of $\mathrm{CBM}$ in China.

\section{Role of Water in CBM Formation}

Coalbed methane forms as either biogenic gas or thermogenic gas [6-9]. The effect of water on the formation of biogenic gas is realized by hydrodynamic conditions, water salinity, and hydrological environments. For the formation of thermogenic gas, the effect of water can be reflected by the heating effect that enhances the coalification process, which further increases the potential of methane generation. The preceding results explain the mechanism of water effect on CBM formation, which is important for selecting the method to extract CBM of different coal ranks.

\subsection{Influence of Water on Biogenic Gases. To compare with} the secondary biogenic gases, primary biogenic gases are hard to be preserved and accumulated to form reservoirs. Studies around the world indicate that active hydrodynamic conditions with proper salinity, a proper $\mathrm{pH}$ value, and oxidation-reduction reactions are beneficial for the formation of secondary biogenic gases in low-rank coals. The hydrodynamic and hydrochemical conditions which are required for producing secondary biogenic gases are as follows: the range of the $\mathrm{pH}$ value from 5.9 to 8.8 is suitable for methanogens to survive and grow as well as the most beneficial range for producing methane [10, 11]. Xianbo et al. conducted an experiment in the laboratory and found that, under the same conditions, the low-rank coal has the maximum methane production capability in the water environment with a $\mathrm{pH}$ of 8 [12]. In a water environment where the oxidation-reduction reactions are lower than $-330 \mathrm{mV}$, the capability of generating secondary biogenic gases is normal; however, when the oxidation-reduction reactions range is from $-540 \mathrm{mV}$ to $-590 \mathrm{mV}$, the methanogens have the highest activity rate and the gas generation capability in low-rank coals reaches the maximum [13]. A temperature range from $36^{\circ} \mathrm{C}$ to $42^{\circ} \mathrm{C}$ is most beneficial for the growth of methanogens [14]. When the salinity does not exceed $4000 \mathrm{mg} / \mathrm{L}$, a large amount of secondary biogenic gases is generated. When the salinity is greater than $10000 \mathrm{mg} / \mathrm{L}$, the gas generation capacity of low-rank coals decreases sharply [15-17]. Taking Powder River Basin in the United States as an example, groundwater is quite active in the slope area on the eastern edge. The salinity in that area is less than $1000 \mathrm{mg} / \mathrm{L}$; thereby, the methanogens are very active, which speeds up the generation of secondary biogenic gases [18]. All these theoretical results provide evidence for selecting the best place for extracting CBM in low-rank coals.
2.2. Influence of Water on Thermogenic Gases. Thermogenic gases are generated mostly during the stage where coal undergoes metamorphism. The heat is the main factor that speeds up the metamorphism process while the groundwater plays an additional role during the formation of thermogenic gases. As fluids carrying the heat, the groundwater directly exchanges heat with coal seams, driving the metamorphism of coal seams. There are two ways for hydrothermal fluids to speed up the metamorphism process: one is the direct contact between coal seams and magma. Magma contains volatiles, which emits high-temperature steams. When the temperature reaches a critical point, high-temperature steams become hydrothermal fluids. This process is also called the pneumatolytic hydrothermal process [19]. The other method is that the water in the coal seam and in the neighboring aquifer becomes high-temperature hydrothermal fluids [20] because the water temperature is increased due to influences from the heat source in the depth of the ground.

\section{Hydrogeological Controls on CBM Enrichment}

3.1. Relationship between Hydrodynamic Zones and CBM Enrichment. Hydrodynamic conditions affect the distribution of methane in coal seams by controlling groundwater movements and changing fluid pressure. To provide evidence for exploring the mechanisms of groundwater movement and finding CBM enrichment zones, this paper carefully divides Qinshui Basin into several hydrodynamic zones.

3.1.1. Classification of Hydrodynamic Fields. At present, representative views on the controlling effect of hydrodynamic zones on the enrichment of CBM in China are as follows: the sealing or plugging of hydraulic flows creates a favorable environment for CBM enrichment. The hydraulic forces cause the methane to migrate and dissipate, resulting in the destruction of CBM reservoirs [21]. Taking the southern Qinshui Basin as an example, domestic scholars divide the basin into three zones based on the geological structure, salinity, and runoff intensity: strong runoff zone, medium runoff zone, and weak runoff zone. The strong runoff zone is located within the belt of $3 \mathrm{~km}-5 \mathrm{~km}$ of the basin margin. Within the zone, the salinity generally ranges from $357 \mathrm{mg} / \mathrm{L}$ to $542 \mathrm{mg} / \mathrm{L}$, and the average gas content in main coal seams ranges from 6 to $8 \mathrm{~m}^{3} / \mathrm{t}$. The medium runoff zone is located at the slope zone around the basin with a width range from $3 \mathrm{~km}$ to $8 \mathrm{~km}$. In the zone, the runoff condition is relatively strong, and the salinity is generally between $466 \mathrm{mg} / \mathrm{L}$ and $1399 \mathrm{mg} / \mathrm{L}$. What is more, the gas content in the coal seam varies greatly, ranging from 3 to $16 \mathrm{~m}^{3} / \mathrm{t}$. The weak runoff zone is located at the internal of the basin, which is abundant in groundwater. The salinity in the zone reaches $1824 \mathrm{mg} / \mathrm{L}$. Due to weak groundwater runoff, the content of CBM in this zone is generally high, reaching $26 \mathrm{~m}^{3} / \mathrm{t}[22,23]$.

On the basis of hydrodynamic zoning at the basin level, domestic scholars worked out a block-level method for identifying hydrodynamic zones according to exploration and 
practice data. Based on the ground pressure data collected in the field testing, they calculated the converted water table and drew the converted water table map to analyze the groundwater flowing state [14]. Then, they divided the groundwater hydrodynamic fields into three zones according to the following conditions such as the structure, hydrochemical characteristics, and runoff intensity in the basin (see Table 1): strong runoff zone, medium runoff zone, and stagnant zone [22-25].

3.1.2. CBM Reservoir Formation Pattern Based on Hydrodynamic Zones. A hydrodynamic condition is one of the main factors controlling the formation of CBM reservoirs. In general, scholars associate hydrodynamic conditions with structural conditions to figure out the formation pattern of CBM reservoirs. Then, they locate the area which is most favorable for CBM enrichment [26]. Fu et al. were the first to propose a conceptual model that combined hydrodynamic conditions with structural conditions. They divided the seal-capping capability of hydraulic runoffs in Qinshui Basin into three types: stagnant runoffs on the pothole-shaped equipotential surface, slow runoffs on the half-graben equipotential surface, and slow runoffs on the fan-shaped equipotential surface [27]. Qin et al. proposed a CBM reservoir formation pattern in which the CBM reservoir was formed because of the seal-capping of hydraulic flows and the imbricate thrust faults in the Zhuozishan mining area, giving a new way of thinking about how to explain the controlling effect of hydrodynamic conditions under complex compositions [28]. Zhu et al. summarized two CBM reservoir formation patterns according to the hydrochemistry, hydrodynamics, and composition characteristics of the Gujiao mining area in the Xi'shan coalfield: monocline structure with hydraulic sealing and horst with hydraulic sealing [29]. Zeng et al. further put forward three CBM enrichment patterns [30]: monocline hydrodynamics, syncline hydrodynamics, and fault hydrodynamics. All the preceding results are of great significance to be referenced when selecting an area with highly enriched CBM.

In the preceding studies, the reservoir formation patterns are classified based on the relationships between geological structures and hydrodynamic zones, which takes fewer considerations on the capping combination condition under the subsidence control, and the scale of CBM reservoirs formed through these patterns is relatively small.

Based on the coupling between geological structures, hydrodynamics, and sedimentary substances, the author dissected the Qinnan-Xiadian area and set up a configured block-level CBM reservoir formation pattern based on main control elements (see Figure 1). The Qinnan-Xiadian area is mainly a syncline structure. One limb of the syncline is cut off by two faults. Combining the geological structure, hydrodynamics, and sedimentary forces, the author divided the limb into three basic systems: open type, semiopen type, and close type. These three basic systems correspond to the recharge zone, weak runoff zone, and pressure-bearing and stagnant zone, respectively, in the figure. The QinnanXiadian block is a delta sedimentary area with the upper roof made by mudstone which has good sealing and capping per- formance. The mudstone roof is distributed stably in the whole zone. The lower floor is made of mudstone or silty mudstone which has a relatively good sealing and capping performance. Therefore, the coupling between geological structures and hydrodynamics is the main factor controlling CBM enrichment in this block. The recharge zone is located at the eastern limb of the syncline. The boundaries of the recharge zone are mainly divided into three types: the water-conducting boundary, jacking overflow boundary, and infiltration recharge boundary. The boundaries are closely related to surface hydraulics. Therefore, the hydraulic activity in the recharge zone is strong, thereby dissolving the methane easily and creating a poor CBM preservation condition. The gas content in the coal seam is less than $8 \mathrm{~m}^{3} / \mathrm{t}$. The gas saturation is less than $48 \%$. The weak runoff zone is located on both sides of the eastern fault. The boundaries are mainly divided into three types: the boundary for gas dissipation, the boundary for sealing water and trapping gases, and the boundary for water discharge and gas leakage. This zone is partly supplemented by atmospheric precipitation. The CBM preservation conditions are relatively good. The gas output from CBM wells is stable. Gas content is greater than $16 \mathrm{~m}^{3} / \mathrm{t}$, and gas is evenly distributed. The pressurebearing and stagnant zone is located at the low-potential area of the syncline. The hydrodynamic runoff conditions in that zone are poor. The boundaries are mainly divided into two types: the boundary for sealing water and trapping gases and the boundary for storing stagnant water. This zone is basically not recharged by atmospheric precipitation. Therefore, it is enriched with CBM. The gas content is greater than $14 \mathrm{~m}^{3} / \mathrm{t}$. The gas saturation is greater than $82 \%$.

3.2. Response Mechanism of Hydrogeochemistry to CBM Enrichment. Hydrogeochemistry features are closely related to CBM. Different groundwater salinity values have varying impacts on CBM enrichment [31]. The isotopic distribution indicates the cause for water produced in coal seams, which further affects the CBM enrichment. Both can indicate the supply source for groundwater, the movement paths of groundwater, and the runoff intensity of groundwater. The groundwater salinity and isotopic distribution can be used to find the CBM enrichment rules under different geological conditions, to figure out the best solution for selecting highly productive and enriched areas of CBM, and to improve the efficiency of extracting and exploring CBM.

\subsubsection{Hydrogeochemical Parameter Characterization and Its} Relationship with CBM Enrichment. Parameters that mainly characterize hydrogeochemistry features include the water type, salinity, and content of main ions. Currently, the common diagrams for determining the water type mainly include a six-axis diagram (Tickel diagram), three-line diagram, Stiff diagram, and Kurlov diagram [31].

This paper employs the Stiff diagram to visually display the differences in the chemical composition of water which is produced from CBM wells in several typical blocks of Qinshui Basin and Ordos Basin. Figure 2 shows the main findings of the study. From the figure, we can see the specific content of main cations and anions in water which is 
TABLe 1: Conditions for identifying different hydrodynamic zones.

\begin{tabular}{|c|c|c|c|}
\hline $\begin{array}{l}\text { Identification } \\
\text { condition }\end{array}$ & Strong runoff zone & Medium runoff zone & Stagnant zone \\
\hline $\begin{array}{l}\text { Fault } \\
\text { development } \\
\text { characteristics }\end{array}$ & $\begin{array}{l}\text { Strongly fractured fault with a high } \\
\text { hydraulic conductivity }\end{array}$ & $\begin{array}{l}\text { Fractures and faults distributed within the zone } \\
\text { with a relatively low hydraulic conductivity }\end{array}$ & $\begin{array}{l}\text { No fractures or fewer fractures } \\
\text { within the zone }\end{array}$ \\
\hline $\begin{array}{l}\text { Connection with } \\
\text { surface water }\end{array}$ & $\begin{array}{l}\text { Close relationship between the } \\
\text { surface water in the zone and the } \\
\text { aquifer }\end{array}$ & $\begin{array}{l}\text { Hydraulic relationships between part of the } \\
\text { surface water in the zone and the aquifer }\end{array}$ & $\begin{array}{c}\text { No hydraulic relationship } \\
\text { between the surface water and } \\
\text { the aquifer }\end{array}$ \\
\hline Water type & $\mathrm{SO}_{4} \cdot \mathrm{Cl}^{-}-\mathrm{Na} \cdot \mathrm{K}$ & $\mathrm{HCO}_{3} \cdot \mathrm{Cl}-\mathrm{Na} \cdot \mathrm{K}$ & $\mathrm{Cl}-\mathrm{Na} \cdot \mathrm{K}$ \\
\hline $\begin{array}{l}\text { Converted } \\
\text { hydraulic } \\
\text { gradient }\end{array}$ & $>0.3 \mathrm{~m} / \mathrm{m}$ & $0.1 \sim 0.3 \mathrm{~m} / \mathrm{m}$ & Less than $0.1 \mathrm{~m} / \mathrm{m}$ \\
\hline Salinity & Low & Medium & High \\
\hline
\end{tabular}

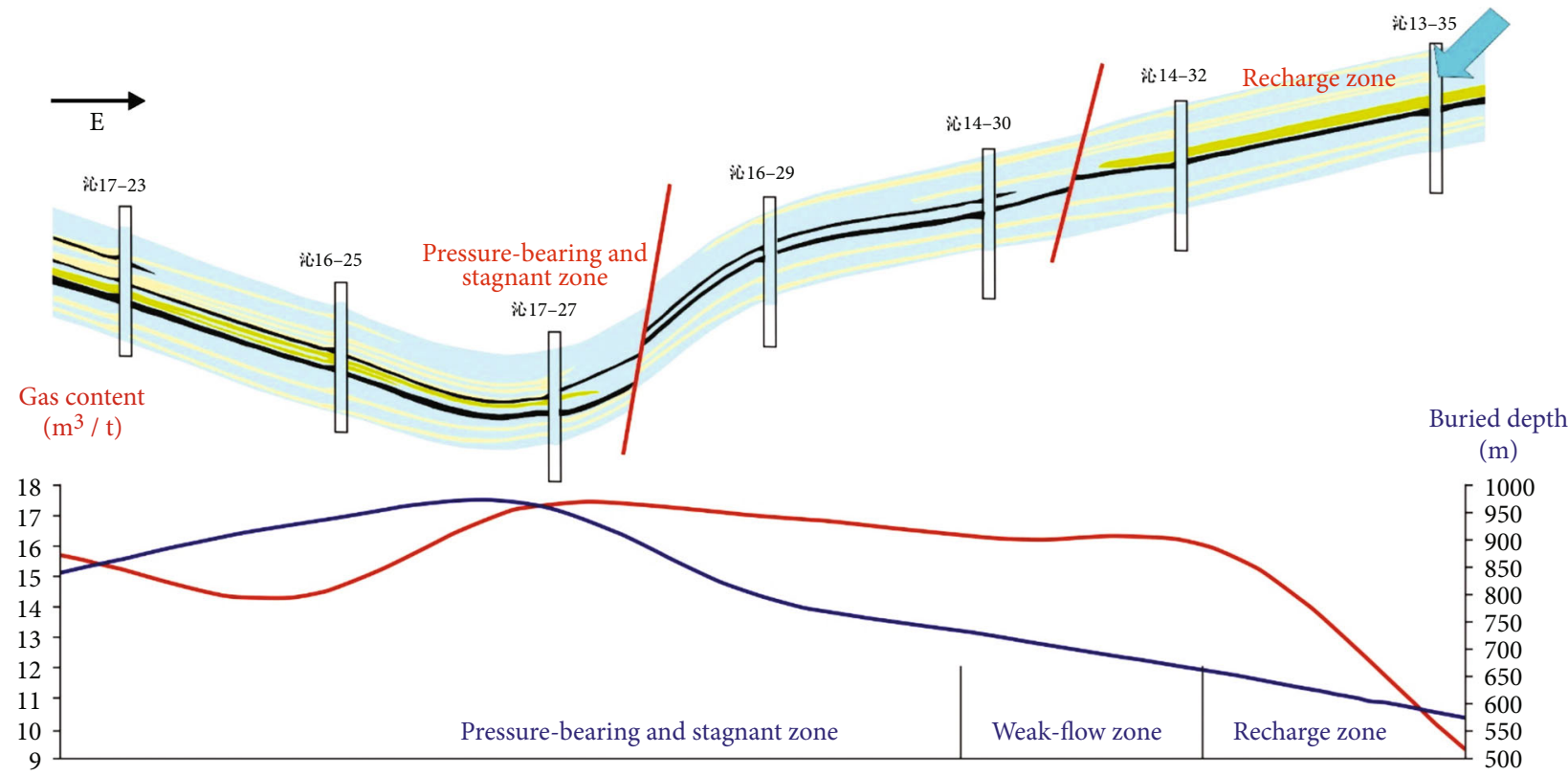

FIgUre 1: Analysis map of the accumulation model of the Qinnan-Xiadian area.

produced from different blocks and the corresponding Stiff diagrams. It can be concluded from Figure 2 that blocks that were highly developed have similar hydrogeochemical characteristics. Water in the CBM enrichment areas is mainly classified into two types: $\mathrm{Na}-\mathrm{HCO}_{3}$ and $\mathrm{Na}-\mathrm{Cl}-\mathrm{HCO}_{3}$. For both water types, the cation characteristics are as follows: $\mathrm{Na}^{+}$and $\mathrm{K}^{+}$are the dominating cations, accounting for more than $90 \%$ of the total amount of cations. The content of $\mathrm{Mg}^{2+}$ and $\mathrm{Ca}^{2+}$ is very low, which accounts for less than $10 \%$ of the total amount of cations. The anion characteristics are as follows: $\mathrm{HCO}_{3}{ }^{-}$is the dominating anion, or $\mathrm{Cl}^{-}$and $\mathrm{HCO}_{3}{ }^{-}$are the dominating anions.

Salinity can be used as an important reference to determine the sealing conditions and hydrodynamic conditions of coal reservoirs. Generally speaking, the areas with stagnant groundwater have high salinity; thus, CBM is more likely to be enriched. However, in the areas close to the recharge zone or the areas with intense groundwater runoffs,
CBM can be easily dissipated along with groundwater movements. CBM is not easy to be preserved. Domestic scholars have reached similar conclusions through sampling and analyzing the water which is produced from CBM wells in places with relatively simple geological structural conditions such as Fanzhuang, Shijiazhuang, Panzhuang, and Shizhuangnan [32-36] in Qinshui Basin: CBM is more enriched in the areas which have the following conditions: the salinity is greater than $1500 \mathrm{mg} / \mathrm{L}$, the desulfurization coefficient is less than 1 , and the coefficient of sodium and chloride is less than 10 (see Table 2).

3.2.2. Response Mechanism of Isotope Geochemistry. The stable isotope compositions of hydrogen and oxygen can provide evidence for the mixture of CBM well-produced water and atmospheric precipitation or groundwater in the surrounding rock aquifers, thus indicating changes in the permeability and water flow rate. In addition, the stable 


\begin{tabular}{|c|c|c|c|c|}
\hline Block Name & $\underset{\left(\mathrm{m} g \cdot \mathrm{L}^{-1}\right)}{\operatorname{main}}$ & $\underset{\left(\mathrm{mg} \cdot \mathrm{L}^{-1}\right)}{\operatorname{main}}$ & stiff diagram & water type \\
\hline $\begin{array}{l}\text { Fanzhuang } \\
\text { block }\end{array}$ & $\begin{array}{l}\frac{\mathrm{Na}+\mathrm{K}^{\prime}}{262.1 \sim 1141} \\
\frac{\mathrm{Mg}^{2-}}{0.5 \sim 38.2} \\
\frac{\mathrm{Ca}^{2-}}{0.8 \sim 30.2}\end{array}$ & $\begin{array}{l}\frac{\mathrm{SO}_{4}^{2 .}}{0.9 \sim 763} \\
\frac{\mathrm{Cl}}{37.3 \sim 1096} \\
\mathrm{HCO}_{3} \\
200.8 \sim 1689\end{array}$ & 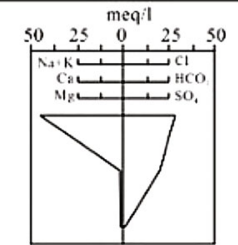 & $\mathrm{Na}-\mathrm{Cl}-\mathrm{HCO}_{3}$ \\
\hline $\begin{array}{l}\text { Zhengzhuang } \\
\text { block }\end{array}$ & $\begin{array}{c}\mathrm{Na}^{+}+\mathrm{K}^{+} \\
434.3 \sim 861 \\
\mathrm{Mg}^{2-} \\
\text { 1. } 5 \sim 28.7 \\
\frac{\mathrm{Ca}^{2-}}{3.1 \sim 32.6}\end{array}$ & $\begin{array}{c}\mathrm{SO}_{4}^{2-} \\
\text { 4. } 2 \sim 239.7 \\
\mathrm{Cl}^{-} \\
\text {42. } 7 \sim 127.5 \\
\frac{\mathrm{HCO}_{3}}{740.3 \sim 1507}\end{array}$ & 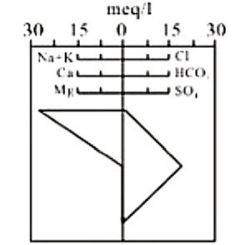 & $\mathrm{Na}-\mathrm{HCO}_{3}$ \\
\hline $\begin{array}{l}\text { Hancheng } \\
\text { block }\end{array}$ & $\begin{array}{c}\mathrm{Na}^{\prime}+\mathrm{K}^{\prime} \\
388.5 \sim 1343.5 \\
\mathrm{Mg}^{2-} \\
1.1 \sim 38.6 \\
\mathrm{Ca}^{2-} \\
5.25 \sim 44.4\end{array}$ & $\begin{array}{c}\mathrm{SO}_{4}^{2 .} \\
0.5 \sim 570 \\
\mathrm{Cl}^{-} \\
97.2 \sim 1612 \\
\mathrm{HCO}_{3} \\
318 \sim 1504\end{array}$ & 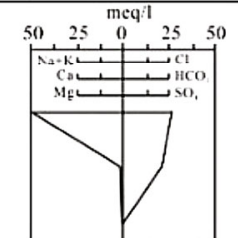 & $\mathrm{Na}-\mathrm{Cl}-\mathrm{HCO}_{3}$ \\
\hline $\begin{array}{l}\text { Baode } \\
\text { block }\end{array}$ & $\begin{array}{c}\frac{\mathrm{Na}^{+}+\mathrm{K}^{\prime}}{105 \sim 604} \\
\mathrm{Mg}^{2-} \\
24 \sim 92.8 \\
\mathrm{Ca}^{2-} \\
22 \sim 144\end{array}$ & $\begin{array}{c}\frac{\mathrm{SO}_{4}^{2 \cdot}}{1 \sim 189} \\
\mathrm{Cl}^{\circ} \\
114 \sim 930 \\
\mathrm{HCO}_{3}^{\circ} \\
180 \sim 1073\end{array}$ & 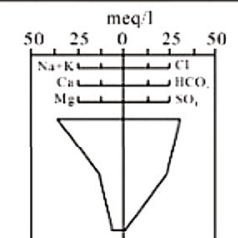 & $\mathrm{Na}-\mathrm{Cl}-\mathrm{HCO}_{3}$ \\
\hline
\end{tabular}

FIgURE 2: Geochemical characteristics of groundwater in typical blocks of North China.

isotope compositions of hydrogen and oxygen are also effective indicators for determining the changes of runoff conditions of CBM well-produced water [36-38]. The stable isotope analysis of CBM well-produced water shows that positive deviations of $\delta^{18} \mathrm{O}$ and $\delta \mathrm{D}$ values in the groundwater are related to high water yield and low gas yield in CBM wells, while negative deviations of $\delta^{18} \mathrm{O}$ and $\delta \mathrm{D}$ values in the groundwater are related to low water yield and high gas yield in CBM wells [39]. These conclusions are based on the measured data and theoretical analysis. Some scholars find that shallow strata and areas with more active groundwater are greatly affected by surface water. The hydrogen and oxygen isotope ratios in produced water are high, showing positive deviations of $\delta^{18} \mathrm{O}$ and $\delta \mathrm{D}$ from the global meteoric water line. However, in the deep strata which have a weak hydraulic connection with surface water, hydrogen and oxygen isotope ratios of produced water are low. It shows negative deviations of $\delta^{18} \mathrm{O}$ and $\delta \mathrm{D}$ on the global precipitation curve. It means that the measured values of $\delta^{18} \mathrm{O}$ and $\delta \mathrm{D}$ are lower than the reference values on GMWL. Considering the relationship between hydrodynamics and coalbed methane enrichment and high production, hydrogen and oxygen isotopes are proposed indicators showing coalbed methane enrichment and high production.

Figure 3 shows the $\mathrm{H}$ and $\mathrm{O}$ isotopes in coal seamproduced water from CBM wells in Qinshui Basin which is located at the central Guizhou uplift area and Bowen Basin in Australia. From Figure 3, we can see that $\delta^{18} \mathrm{O}$ and $\delta \mathrm{D}$ values in Qinshui Basin are lower, with $\delta \mathrm{D}$ ranging from $-80 \%$ to $-75 \%$ and $\delta^{18} \mathrm{O}$ ranging from $-12 \%$ to $-8 \%$. CBM wells are distributed on both sides of the global atmospheric precipitation line. Most of the CBM wells are at the right of the curve, indicating that the reason for forming coalbed water is complex. Most of the water is produced by sedimentation; however, the water in some wells is produced by infiltration. For the central Guizhou uplift area, there is a relatively large variation in hydrogen and oxygen isotopes, with $\delta \mathrm{D}$ ranging from $-90 \%$ o to $-30 \%$ and $\delta^{18} \mathrm{O}$ ranging from $-11 \%$ to $-4 \%$. The wells are mainly distributed at the left of the global meteoric water line. The $\delta \mathrm{D}$ has obvious $D$ drifting characteristics, indicating that the coalbed water is mainly recharged by atmospheric precipitation as well as a strong interaction between water and rock [40]. The $\delta^{18} \mathrm{O}$ and $\delta \mathrm{D}$ values in Bowen Basin CBM water are relatively higher, with $\delta \mathrm{D}$ ranging from $-50 \%$ to $-30 \%$ o and $\delta^{18} \mathrm{O}$ ranging from $-8 \%$ to $-4 \%$. The wells are mainly distributed near the global meteoric water line. The $\delta \mathrm{D}$ tends to shift to the right, indicating that the coalbed water is recharged by surface water, and most of the water is produced in sedimentary processes. The hydrogen and oxygen isotopes in atmospheric precipitation are relatively light, while the hydrogen and oxygen isotopes in sedimentary water are relatively heavy due to the influence of fractionation. Therefore, the source of coalbed water can be judged 
TABLE 2: Geochemical characteristics of water produced from CBM wells in Qinshui Basin [4, 32-35].

\begin{tabular}{|c|c|c|c|c|c|c|c|c|c|c|}
\hline \multirow[t]{2}{*}{ Block } & \multirow[t]{2}{*}{$\begin{array}{l}\text { Well sequence } \\
\text { number }\end{array}$} & \multicolumn{6}{|c|}{ Major ion concentration $\left(\mathrm{mg} \cdot \mathrm{L}^{-1}\right)$} & \multirow[t]{2}{*}{$\begin{array}{l}\text { Salinity } \\
\left(\mathrm{mg} \cdot \mathrm{L}^{-1}\right)\end{array}$} & \multirow[t]{2}{*}{$\begin{array}{l}\text { Coefficient for } \\
\text { sodium-chloride }\end{array}$} & \multirow[t]{2}{*}{$\begin{array}{c}\text { Desulfurization } \\
\text { coefficient }\end{array}$} \\
\hline & & $\mathrm{Na}^{+}+\mathrm{K}^{+}$ & $\mathrm{Mg}^{2+}$ & $\mathrm{Ca}^{2+}$ & $\mathrm{Cl}^{-}$ & $\mathrm{HCO}_{3}^{-}$ & $\mathrm{SO}_{4}{ }^{2-}$ & & & \\
\hline \multirow{6}{*}{ Fanzhuang } & FZ-1 & 537.7 & 4.6 & 8.65 & 129 & 1130.3 & 1.12 & 1811.37 & 6.43 & 0.32 \\
\hline & FZ-2 & 703.9 & 4.65 & 11.9 & 308 & 1341 & 0.94 & 2370.39 & 3.35 & 0.11 \\
\hline & FZ-3 & 551.1 & 1.47 & 4.13 & 119 & 1185.1 & 0.82 & 1861.62 & 7.15 & 0.25 \\
\hline & FZ-4 & 640 & 2.20 & 4.01 & 248 & 1115.9 & 7.46 & 2071.57 & 3.98 & 1.11 \\
\hline & FZ-5 & 1061.5 & 6.55 & 10.3 & 981 & 1019.1 & 1.62 & 3080.07 & 1.67 & 0.06 \\
\hline & FZ-6 & 598.07 & 2.45 & 4.66 & 75.5 & 1366.2 & 4.47 & 2051.35 & 12.23 & 2.19 \\
\hline \multirow{7}{*}{$\begin{array}{l}\text { North of } \\
\text { Shijiazhuang }\end{array}$} & SJZ-1 & 476.26 & 2.36 & 7.7 & 37.7 & 1143 & 4.95 & 1718 & 19.5 & 4.86 \\
\hline & SJZ-2 & 391.79 & 2.50 & 7.88 & 42.3 & 938 & 0.86 & 1418 & 14.3 & 0.76 \\
\hline & SJZ-3 & 478.18 & 3.19 & 7.38 & 43.9 & 1081 & 1.69 & 1683 & 16.81 & 1.42 \\
\hline & SJZ-4 & 430.04 & 2.75 & 7.06 & 42.9 & 978 & 2.73 & 1516 & 15.47 & 2.35 \\
\hline & SJZ-5 & 410.09 & 1.96 & 6.17 & 52.3 & 959 & 1.68 & 1469 & 12.10 & 1.19 \\
\hline & SJZ-6 & 402.63 & 1.87 & 6.17 & 5.02 & 932 & 4.62 & 1437 & 123.79 & 34.03 \\
\hline & SJZ-7 & 419.22 & 2.94 & 8.12 & 36.7 & 953 & 0.7 & 1482 & 17.63 & 0.71 \\
\hline \multirow{6}{*}{$\begin{array}{l}\text { South of } \\
\text { Shijiazhuang }\end{array}$} & SJZ-8 & 483.71 & 2.83 & 9.08 & 38.6 & 1145 & 2.5 & 1738 & 19.34 & 2.4 \\
\hline & SJZ-9 & 405.08 & 2.05 & 5.81 & 33.7 & 968 & 8.82 & 1452 & 18.55 & 9.68 \\
\hline & SJZ-10 & 424 & 1.80 & 5.60 & 39.9 & 1009 & 2.07 & 1520 & 16.40 & 1.92 \\
\hline & SJZ-11 & 394.67 & 2.08 & 7.44 & 35.2 & 906 & 0.68 & 1395 & 17.31 & 0.71 \\
\hline & SJZ-12 & 380.05 & 2.02 & 7.89 & 36.2 & 885 & 1.57 & 1358 & 16.20 & 1.60 \\
\hline & SJZ-13 & 401.18 & 2.50 & 6.4 & 36 & 904 & 0.33 & 1409 & 17.20 & 0.34 \\
\hline \multirow{6}{*}{ Panzhuang } & PZ-1 & 821.3 & 7.70 & 11.3 & 322.2 & 1313.7 & 189.3 & 2742 & 3.93 & 21.73 \\
\hline & PZ-2 & 610.2 & 1.05 & 5.14 & 60.50 & 1384 & 0.59 & 2130 & 15.57 & 0.36 \\
\hline & PZ-3 & 635.92 & 4.21 & 8.09 & 136 & 1443 & 20.9 & 2258 & 7.22 & 5.68 \\
\hline & PZ-4 & 614.41 & 5.14 & 5.02 & 138 & 1225 & 44.9 & 2112 & 6.87 & 12.03 \\
\hline & PZ-5 & 589.84 & 7.53 & 5.89 & 72.3 & 1244 & 57.3 & 2067 & 12.59 & 29.31 \\
\hline & PZ-6 & 716.63 & 29.2 & 41.4 & 110 & 997 & 796 & 2697 & 10.06 & 267.59 \\
\hline \multirow{5}{*}{$\begin{array}{l}\text { South of } \\
\text { Sizhuang }\end{array}$} & SZ-1 & 419.29 & 0.43 & 2.59 & 93.52 & 599.86 & 0.68 & 4208 & 6.92 & 0.27 \\
\hline & SZ-2 & 278.61 & 0.17 & 2.14 & 86.7 & 555.04 & 0.52 & 5553 & 4.96 & 0.22 \\
\hline & SZ-3 & 318.3 & 0.3 & 2.29 & 81.03 & 561.94 & 3.6 & 2425 & 6.06 & 1.64 \\
\hline & SZ-4 & 747.95 & 4.24 & 2.87 & 336.55 & 1082.5 & 0.62 & 2294 & 3.43 & 0.07 \\
\hline & SZ-5 & 443.03 & 0.35 & 2.65 & 70.35 & 810.15 & 0.26 & 1059 & 9.72 & 0.14 \\
\hline
\end{tabular}

Data source from the literature [32-35].

based on the relationship between the hydrogen and oxygen isotopes and the atmospheric precipitation curve.

\section{Hydrogeological Effects of High CBM Production}

4.1. Water Production Features of High CBM-Production Areas. The average water production in the stage of drainage and pressure reduction is used as the basis for dividing CBM wells into three types: high-yield wells, medium-yield wells, and low-yield wells. The low-yield wells are CBM wells with an average daily discharge of less than $2 \mathrm{~m}^{3} / \mathrm{d}$ of water during the drainage stage. The medium-yield wells are CBM wells with an average daily discharge of $2 \sim 5 \mathrm{~m}^{3} / \mathrm{d}$ of water during the drainage stage. The high-yield wells are CBM wells with an average daily discharge of more than $5 \mathrm{~m}^{3} / \mathrm{d}$ of water during the drainage stage. Taking the Fanzhuang block as an example, thirty-one high-yield CBM wells (the average daily water production before the entrance of CBM wells into the production decline stage was greater than $1000 \mathrm{~m}^{3} / \mathrm{d}$ ) are statistically analyzed (see Tables $1-3$ ), and the water production curve is drawn. Among these wells, five wells are wells with a high gas production and high water yield, which are mainly located at the lower part of the local structure. The average daily water production of a single well is between $7.54 \mathrm{~m}^{3} / \mathrm{d}$ and $9.74 \mathrm{~m}^{3} / \mathrm{d}$ during the stage of drainage and pressure reduction. Ten wells are wells with a high gas production and medium water yield, which are located near the middle and higher parts of the local structure. The average daily water production of a single well is between $2.09 \mathrm{~m}^{3} / \mathrm{d}$ and $4.83 \mathrm{~m}^{3} / \mathrm{d}$ during the stage of drainage and pressure reduction. Eighteen wells are wells with a high gas production and low water yield, which are mainly located in the higher part of the local structure above the 


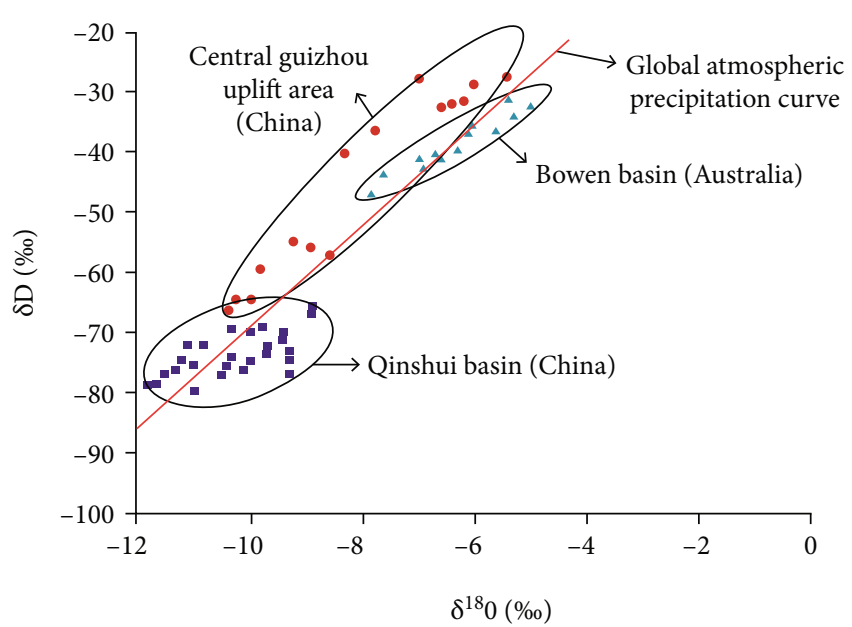

FIgURE 3: Diagrams of $\mathrm{H}$ and $\mathrm{O}$ isotopes in coal seam-produced water in different coal basins in China and Australia [38-40].

groundwater level. The average daily water production of a single well is between $0.09 \mathrm{~m}^{3} / \mathrm{d}$ and $1.93 \mathrm{~m}^{3} / \mathrm{d}$ during the stage of drainage and pressure reduction.

After analyzing the extraction characteristics of selected wells and well structures, the author summarized the following high CBM-production patterns: (1) coalbed structurehydraulic trapping (see Figure 4(a)), (2) fold limb-fracture development (see Figure 4(b)), and (3) syncline core-water stagnation (see Figure 4(c)).

The area with the first CBM production pattern is located at the higher part of an asymmetric syncline or monocline where the fractures are not developed or waterresistant faults are developed. In Figure 4(a), CBM wells are placed in the higher part of the monocline and far away from the water-resistant fault and recharge source. According to the CBM and the mechanism of water movement, the coalbed water moves from the high-potential zone to the low-potential zone while CBM moves in the opposite direction [41]. However, due to the blocking function of the fault, the hydraulic connection between the hanging wall of the fault and the footwall of the fault is weak. The coalbed water is in a stagnant state in the hanging wall of the fault, which is beneficial for enriching the CBM, resulting in a high CBM content. At the same time, atmospheric precipitation forms hydraulic trapping forces for CBM that moves upwards along the monoclinal structure, preventing CBM in the lower-potential zone from dissipating during the extraction process, which is beneficial for high CBM production in the higher-potential zone. In addition, the coal seam in the higher part of the structure has a better permeability due to the lower pressure and the movements of water and gas. In this pattern, the rules for forming CBM in CBM wells are reflected as follows: a short gas breakthrough time, a low water yield, and a high gas yield. Affected by free gases, the coal seam may have a $100 \%$ of gas production.

The area with the second CBM production pattern is located at the limb of a syncline or anticline affected by tensile stress. In Figure 4(b), CBM wells are arranged in the limb of the syncline. Affected by tensile stress, fractures are developed in the coalbed layer and the buried depth of coals is shallow, which is generally about $300 \mathrm{~m}-800 \mathrm{~m}$. The limb of the syncline is less affected by coalbed water. However, affected by free gases in the core of the syncline, there are more and more CBM formation sources. The fractures generated by the forces of tensile stress are developed on a large scale, leading to the fracturing of reservoirs and further resulting in the desorption of a large amount of CBM [41-43]. In this pattern, the rules for forming CBM in CBM wells are reflected as follows: a short gas breakthrough time in the preliminary stage, an increasing daily yield of gas, and a high peak of gas production.

The area with the third CBM production pattern is located near the core of a synclinore and secondary syncline in a large sedimentary basin. In Figure 4(c), CBM wells are arranged in the core of a broad and gentle syncline where stagnant water stays. No fault is developed, the sealing and capping capability of the roof is good, and the salinity is high. In a situation where the roof has a good waterresistant condition, CBM wells are less affected by external water and the exploitation of CBM wells is not affected. The high effective thickness of the upper layer, the buried depth of the coal seam, and the forces of tensile stress are all beneficial for enriching CBM. In this pattern, the rules for forming CBM in CBM wells are reflected as follows: a high water yield with a long time to enter the stable production phase, a low CBM yield and a high water yield at the beginning, and a long stable production phase with a high peak of gas production and stable gas yield.

\subsection{Hydrochemical Features of Areas with a High CBM} Yield. The hydrochemical coefficients can better reflect the sealing conditions of groundwater. For example, the coefficient of sodium and chloride can reflect the enrichment degree of sodium salt in groundwater, the metamorphic grade of groundwater, and the hydrogeochemical environment of the reservoir. The desulfurization coefficient is an important index to reflect the openness of groundwater. In general, a better formation closure has the following characteristics: a more thorough desulfurization, a lower $\mathrm{SO}_{4}{ }^{2-}$ content, a smaller desulfurization coefficient, and a more intense reducing action [14].

A comprehensive analysis of hydrochemical characteristics and gas content in the southern part of the Fanzhuang block reveals that the salinity in the southern part of the block gradually increases from north to south, and the sodium-chloride coefficient gradually decreases from northwest to southeast. Two CBM enrichment centers are formed in the area with a high salinity (shown in Figure 5). The area with salinity greater than $2000 \mathrm{mg} / \mathrm{L}$ is the CBM stagnation area, and the coalbed gas content is above $26 \mathrm{~m}^{3} / \mathrm{t}$. The above information shows that the area with high salinity and the area with high CBM are positively correlated. However, CBM wells in the area with the highest salinity are not highly productive. The areas with high CBM production in the south of the Fanzhuang block are the intersecting areas with a medium salinity of $2000-3500 \mathrm{mg} / \mathrm{L}$ and $\mathrm{rNa} / \mathrm{rCl}$ less than 6 .

Taking the Fanzhuang block in Qinshui Basin as an example, we discussed the controlling effects of the 
TABLE 3: CBM well gas and water productivity in the Fanzhuang block.

\begin{tabular}{|c|c|c|c|c|c|c|c|}
\hline \multirow[b]{2}{*}{ No. } & \multicolumn{2}{|c|}{ Gas production } & \multirow[b]{2}{*}{$\begin{array}{c}\text { Total water } \\
\text { production }\left(\mathrm{m}^{3}\right)\end{array}$} & \multirow[b]{2}{*}{$\begin{array}{l}\text { Gas-water } \\
\text { ratio }\end{array}$} & \multicolumn{3}{|c|}{ Drainage and pressure reduction stage } \\
\hline & $\begin{array}{l}\text { Average } \\
\left(\mathrm{m}^{3} / \mathrm{d}\right)\end{array}$ & $\begin{array}{l}\text { Total } \\
\left(\mathrm{m}^{3}\right)\end{array}$ & & & $\begin{array}{l}\text { Number of } \\
\text { days (d) }\end{array}$ & $\begin{array}{l}\text { Total discharged } \\
\text { water }\left(\mathrm{m}^{3}\right)\end{array}$ & $\begin{array}{l}\text { Average daily discharged } \\
\text { water }\left(\mathrm{m}^{3} / \mathrm{d}\right)\end{array}$ \\
\hline $\begin{array}{l}\text { FZ- } \\
1\end{array}$ & 1238 & 1770555 & 967.4 & 1830.2 & 210 & 468.00 & 2.23 \\
\hline $\begin{array}{l}\text { FZ- } \\
2\end{array}$ & 1627 & 2241711 & 496.8 & 4512.3 & 240 & 440.30 & 1.83 \\
\hline $\begin{array}{l}\text { FZ- } \\
3\end{array}$ & 1233 & 1541258 & 556.1 & 2771.5 & 193 & 403.70 & 2.09 \\
\hline $\begin{array}{l}\text { FZ- } \\
4\end{array}$ & 2238 & 2715371 & 899.1 & 3020.1 & 233 & 595.90 & 2.56 \\
\hline $\begin{array}{l}\text { FZ- } \\
5\end{array}$ & 1942 & 2832225 & 600.3 & 4718 & 258 & 499.20 & 1.93 \\
\hline $\begin{array}{l}\text { FZ- } \\
6\end{array}$ & 1107 & 1877232 & 563.3 & 3332.6 & 279 & 446.30 & 1.60 \\
\hline $\begin{array}{l}\text { FZ- } \\
7\end{array}$ & 1236 & 1436079 & 817.2 & 1757.3 & 393 & 549.30 & 1.40 \\
\hline $\begin{array}{l}\text { FZ- } \\
8\end{array}$ & 1029 & 1099688 & 648.0 & 1697.1 & 366 & 320.70 & 0.88 \\
\hline $\begin{array}{l}\text { FZ- } \\
9\end{array}$ & 2116 & 1410890 & 62.6 & 22538.1 & 48 & 14.60 & 0.30 \\
\hline $\begin{array}{l}\text { FZ- } \\
10\end{array}$ & 2799 & 964503 & 57.1 & 16891.5 & 83 & 15.80 & 0.19 \\
\hline $\begin{array}{l}\text { FZ- } \\
11\end{array}$ & 1141 & 4330482 & 3897.9 & 1111 & 1451 & 3276.40 & 2.26 \\
\hline $\begin{array}{l}\text { FZ- } \\
12\end{array}$ & 1344 & 5896287 & 2404.1 & 2452.6 & 1144 & 1707.00 & 1.49 \\
\hline $\begin{array}{l}\text { FZ- } \\
13\end{array}$ & 1008 & 3627541 & 5223.2 & 694.5 & 936 & 2971.20 & 3.17 \\
\hline $\begin{array}{l}\text { FZ- } \\
14\end{array}$ & 1544 & 6624604 & 6084.1 & 1088.8 & 991 & 4634.20 & 4.68 \\
\hline $\begin{array}{l}\text { FZ- } \\
15\end{array}$ & 1858 & 7349913 & 3661.6 & 2007.3 & 1935 & 3288.00 & 1.70 \\
\hline $\begin{array}{l}\text { FZ- } \\
16\end{array}$ & 1064 & 3740135 & 10178 & 367.5 & 1896 & 9162.50 & 4.83 \\
\hline $\begin{array}{l}\text { FZ- } \\
17\end{array}$ & 1346 & 2349283 & 2982.9 & 787.6 & 456 & 1174.70 & 2.58 \\
\hline $\begin{array}{l}\text { FZ- } \\
18\end{array}$ & 5399 & 583072 & 138.3 & 4216.0 & 176 & 107.90 & 0.61 \\
\hline $\begin{array}{l}\text { FZ- } \\
19\end{array}$ & 4938 & 2114079 & 349.9 & 6042.0 & 151 & 13.70 & 0.09 \\
\hline $\begin{array}{l}\text { FZ- } \\
20\end{array}$ & 8249 & 3089116 & 30.0 & 102970.5 & 55 & 11.20 & 0.20 \\
\hline $\begin{array}{l}\text { FZ- } \\
21\end{array}$ & 1025 & 7871921 & 348.6 & 22581.5 & 421 & 233.50 & 0.55 \\
\hline $\begin{array}{l}\text { FZ- } \\
22\end{array}$ & 1250 & 9834482 & 2261.8 & 4348.1 & 1087 & 1825.60 & 1.68 \\
\hline $\begin{array}{l}\text { FZ- } \\
23\end{array}$ & 1020 & 6859558 & 793.4 & 8645.8 & 356 & 478.70 & 1.34 \\
\hline $\begin{array}{l}\text { FZ- } \\
24\end{array}$ & 1224 & 9335585 & 876.3 & 10653.4 & 540 & 427.80 & 0.79 \\
\hline $\begin{array}{l}\text { FZ- } \\
25\end{array}$ & 8284 & 4076042 & 101.4 & 40197.7 & 124 & 29.80 & 0.24 \\
\hline $\begin{array}{l}\text { FZ- } \\
26\end{array}$ & 3855 & 2070627 & 437.5 & 4732.9 & 183 & 253.30 & 1.38 \\
\hline
\end{tabular}


TABLE 3: Continued.

\begin{tabular}{|c|c|c|c|c|c|c|c|}
\hline \multirow[b]{2}{*}{ No. } & \multicolumn{2}{|c|}{ Gas production } & \multirow{2}{*}{$\begin{array}{c}\text { Total water } \\
\text { production }\left(\mathrm{m}^{3}\right)\end{array}$} & \multirow[b]{2}{*}{$\begin{array}{l}\text { Gas-water } \\
\text { ratio }\end{array}$} & \multicolumn{3}{|c|}{ Drainage and pressure reduction stage } \\
\hline & $\begin{array}{l}\text { Average } \\
\left(\mathrm{m}^{3} / \mathrm{d}\right)\end{array}$ & $\begin{array}{l}\text { Total } \\
\left(\mathrm{m}^{3}\right)\end{array}$ & & & $\begin{array}{l}\text { Number of } \\
\text { days (d) }\end{array}$ & $\begin{array}{l}\text { Total discharged } \\
\text { water }\left(\mathrm{m}^{3}\right)\end{array}$ & $\begin{array}{l}\text { Average daily discharged } \\
\text { water }\left(\mathrm{m}^{3} / \mathrm{d}\right)\end{array}$ \\
\hline $\begin{array}{l}\text { FZ- } \\
27\end{array}$ & 10362 & 3348692 & 938.1 & 3569.7 & 251 & 610.80 & 2.43 \\
\hline $\begin{array}{l}\text { FZ- } \\
28\end{array}$ & 8365 & 2751742 & 2394.3 & 1149.3 & 217 & 2034.90 & 9.38 \\
\hline $\begin{array}{l}\text { FZ- } \\
29\end{array}$ & 10682 & 1131285 & 2073.9 & 545.5 & 259 & 1953.10 & 7.54 \\
\hline $\begin{array}{l}\text { FZ- } \\
30\end{array}$ & 8063 & 807480 & 3473.9 & 232.4 & 356 & 3467.00 & 9.74 \\
\hline $\begin{array}{l}\text { FZ- } \\
31\end{array}$ & 6519 & 81626883 & 3621.8 & 22537.7 & 410 & 1754.31 & 4.28 \\
\hline
\end{tabular}

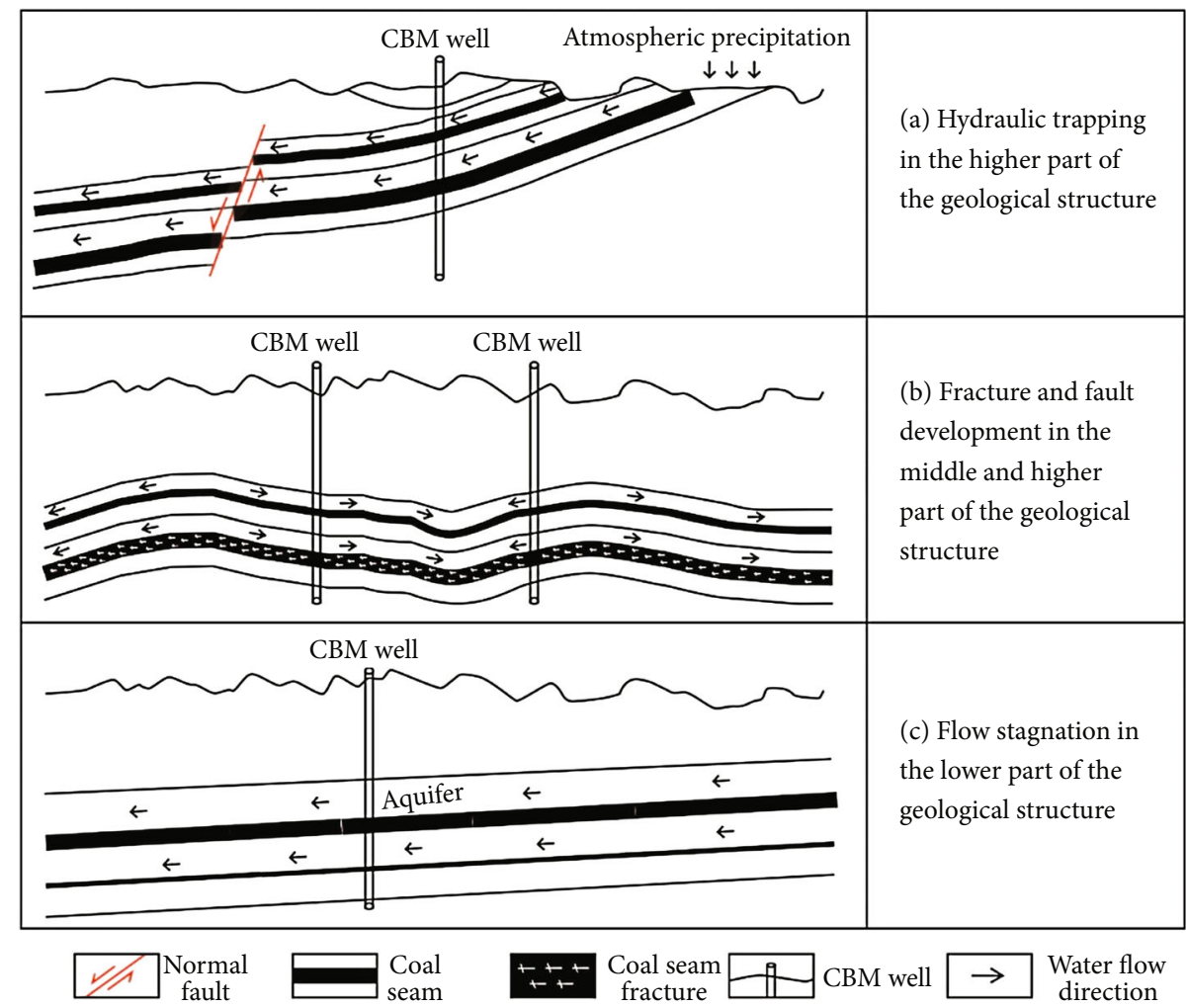

FIgURE 4: Schematic diagram of high-yield patterns of CBM wells.

coefficient of sodium and chloride, the desulfurization coefficient, and the $\mathrm{H}$ and $\mathrm{O}$ isotopes on the high $\mathrm{CBM}$ production in the CBM enrichment area in the southern part of the block. By studying the distribution of these coefficients in the Fanzhuang block, it is found that CBM wells with a high daily gas production are mainly distributed in the area with the coefficient of sodium and chloride ranging from 3.5 to 8 . Besides, the distribution of CBM wells with a high daily gas production has a negative correlation with the sodiumchloride coefficient within a certain range. The lower the sodium-chloride coefficient, the more frequent the highproduction wells appear in the area. The desulfurization coefficient can reflect how enclosed the groundwater envi- ronment is. The Fanzhuang block is located at the area with a desulfurization coefficient between 4 and 10 and a high distribution of high-yield wells. The desulfurization coefficient is also positively related to the daily gas production of a single well. The distribution of hydrogen and oxygen isotopes can reflect the cause for coalbed water generation and its permeability. In general, the densities of hydrogen and oxygen isotopes in coalbed water from different origins are different. The order of the densities should be as follows: the density of water from atmospheric precipitation $>$ the density of surface water $>$ the density of sedimentary water. Among the water from different origins, the permeability of water from atmospheric precipitation is preferred. The 


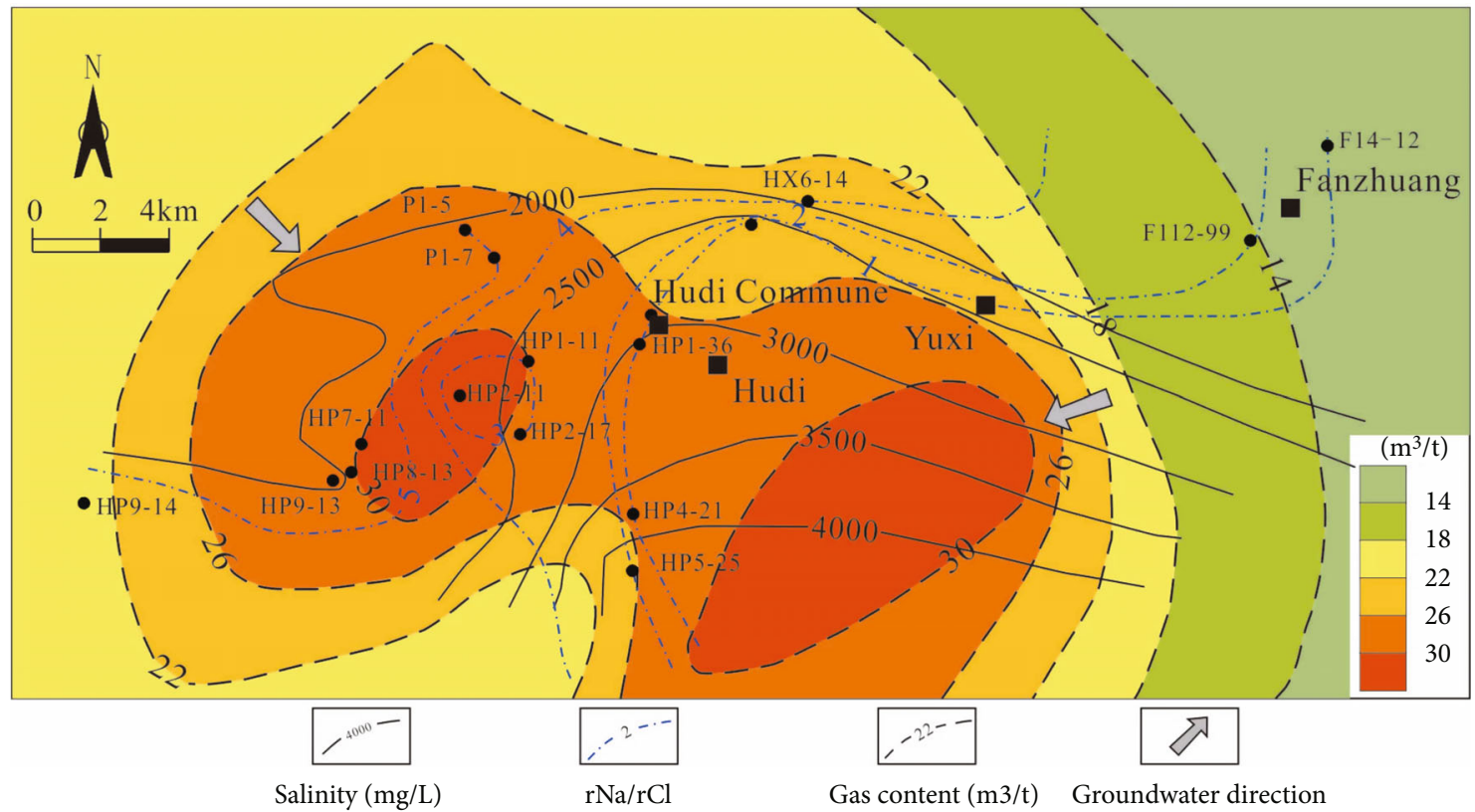

FIGURE 5: Relationship between the salinity of produced water (constant ratio) and the CBM in the south of the Fanzhuang block.

reason is that water from atmospheric precipitation is most conducive to the high production of CBM wells. The higher the permeability in areas with a lighter hydrogen isotope, the higher the CBM production is. The $\delta \mathrm{D}$ value of the Fanzhuang block ranges from $-75 \%$ o to $-77 \%$, which is beneficial for CBM production [14].

In summary, in CBM enrichment areas, it is prone to produce high yields of CBM for the CBM wells with a relatively low sodium-chlorine coefficient, a relatively high desulfurization coefficient, and a good permeability due to water from atmospheric precipitation.

\section{Typical Case Analysis}

5.1. Fanzhuang Block in Qinshui Basin. In the Fanzhuang block of Qinshui Basin, fifty-eight CBM wells with a relatively rich concentration of CBM and permeability greater than $0.1 \mathrm{mD}$ are selected for statistical analysis. Data in the initial stage of the two-phase flow of CBM wells is used for comparison. According to the daily gas production, the wells are divided into three types: high-yield wells (17 wells with daily gas production $>2000 \mathrm{~m}^{3}$ ), medium-yield wells (16 wells with daily gas production between 1000 and $2000 \mathrm{~m}^{3}$ ), and low-yield wells (25 wells with daily gas production $<1000 \mathrm{~m}^{3}$ ).

The gas-water ratio of high-yield wells in the Fanzhuang block is between 212 and 6113 with an average value of 1988 . These wells are mainly located at slopes and the higher part of the geological structure. The gas-water ratio of mediumyield wells is between 91 and 1944, with an average of 625 . These wells are mainly located at slopes and the higher part of the geological structure. The gas-water ratio of low-yield wells is between 40 and 2035, with an average value of 373 . These wells are distributed at slopes and higher parts and lower parts of the geological structure (see Table 4).
By analyzing the statistical results, it is found that the high-yield wells are mainly located at the slope zone and the higher part of the geological structure with a gas-water ratio higher than 500. Low-yield wells are mainly distributed at the lower part of the geological structure with a gas-water ratio of less than 500 . One of the main reasons that cause the difference in gas production of medium-yield and high-yield wells is the dynamic effect of groundwater. The higher part of the geological structure and the slope zone are both conducive to draining away water and lowering the pressure of CBM wells. However, at the higher part of the geological structure, the good hydrodynamic conditions may cause the CBM to disperse along with water flows. In the slope zone, the poor hydrodynamic conditions are beneficial for CBM preservation and high production of wells.

5.2. Hancheng Mining Area in Ordos Basin. According to the research by Li et al. [25], the gas content and gas production of the No. 11 coal seam in the Hancheng mining area on the southeastern margin of Ordos Basin are highly correlated with the chemical composition of its coal seam water. Table 5 describes the relationships between hydrochemical zones and gas content (data from 25 samples). In their study, 249 samples that were used for the statistical study revealed the relationships among hydrochemical characteristics, gas content, and water content (see Table 6) [44].

In the Hancheng mining area, the CBM wells are mainly distributed in the $\mathrm{HCO}_{3}{ }^{-}-\mathrm{Cl}^{-}-\mathrm{Na}^{+}$zone. The wells with the highest gas production are in the $\mathrm{Cl}^{-}-\mathrm{Na}^{+}$zone, and the wells with the second-highest gas production are in the $\mathrm{SO}_{4}{ }^{2-}-\mathrm{Cl}^{-}-\mathrm{Ca}^{2+}-\mathrm{Na}^{+}$zone. On the contrary, the wells with the highest water production are in the $\mathrm{HCO}_{3}{ }^{-}-\mathrm{Na}^{+}$zone, and the wells with the second-highest water production are in the $\mathrm{HCO}_{3}{ }^{-}-\mathrm{Cl}^{-}-\mathrm{Na}^{+}$zone. An obvious negative correlation exists between $\mathrm{CBM}$ production and water production 
TABLE 4: The produced gas-water volume ratio of typical CBM wells and distribution of structural parts in the Fanzhuang block.

\begin{tabular}{lcccc}
\hline Gas production scale & & High-yield wells & Medium-yield wells & Low-yield wells \\
\hline & Higher part & 3 & 6 & 9 \\
Structural parts & Slope & 14 & 1 & 10 \\
& Lower part & 0 & $91 \sim 1944$ & 6 \\
Gas-water ratio & & $212 \sim 6113$ & 625 & $32 \sim 2035$ \\
Average value & & 1988 & 373 \\
\hline
\end{tabular}

TABLE 5: Distribution of gas content in different hydrochemical zones of the No. 11 coal seam in the Hancheng mining area [44].

\begin{tabular}{lcccc}
\hline Hydrochemical zone & $\mathrm{HCO}_{3}{ }^{-}-\mathrm{Na}^{+}$zone & $\mathrm{HCO}_{3}{ }^{-}-\mathrm{Cl}^{-}-\mathrm{Na}^{+}$zone & $\mathrm{SO}_{4}{ }^{2-}-\mathrm{Cl}^{-}-\mathrm{Ca}^{2+}-\mathrm{Na}^{+} \mathrm{zone}^{-} \mathrm{Cl}^{-}-\mathrm{Na}^{+} \mathrm{zone}$ \\
\hline Number of samples & 5 & 10 & 5 & 5 \\
Current gas content $\left(\mathrm{m}^{3} / \mathrm{t}\right)$ & $4 \sim 6$ & $6 \sim 9$ & $8 \sim 13$ & 11.6 \\
Current average gas content $\left(\mathrm{m}^{3} / \mathrm{t}\right)$ & 5.5 & 8.3 & $9 \sim 16$ & 14.1 \\
Original gas content $\left(\mathrm{m}^{3} / \mathrm{t}\right)$ & $11 \sim 15$ & $10 \sim 15$ & 14 & 14.1 \\
Original average gas content $\left(\mathrm{m}^{3} / \mathrm{t}\right)$ & 13.9 & 14 & 16 & 14.3 \\
\hline
\end{tabular}

TABLE 6: Water production and gas production of CBM wells in different hydrochemical zones of the No. 11 coal seam in the Hancheng mining area [44].

\begin{tabular}{|c|c|c|c|c|}
\hline Hydrochemical zone & $\mathrm{HCO}_{3}^{-}-\mathrm{Na}^{+}$zone & $\mathrm{HCO}_{3}{ }^{-}-\mathrm{Cl}^{-}-\mathrm{Na}^{+}$zone & $\mathrm{SO}_{4}{ }^{2-}-\mathrm{Cl}^{-}-\mathrm{Ca}^{2+}-\mathrm{Na}^{+}$zone & $\mathrm{Cl}^{-}-\mathrm{Na}^{+}$zone \\
\hline Number of samples & 10 & 212 & 10 & 17 \\
\hline Average water production $\left(\mathrm{m}^{3} / \mathrm{d}\right)$ & 9.92 & 5.64 & 3.62 & 1.61 \\
\hline Average gas production $\left(\mathrm{m}^{3} / \mathrm{d}\right)$ & 235 & 598 & 1056 & 1983 \\
\hline
\end{tabular}

in the coalfield: the lower the water production, the higher the CBM production is.

By comparing the current gas content of coal seams in different hydrochemical zones, it is found that the $\mathrm{Cl}^{-}-\mathrm{Na}^{+}$ zone has the highest gas content, then followed by the $\mathrm{SO}_{4}{ }^{2-}-\mathrm{Cl}^{-}-\mathrm{Ca}^{2+}-\mathrm{Na}^{+}$zone and $\mathrm{HCO}_{3}{ }^{-}-\mathrm{Cl}^{-}-\mathrm{Na}^{+}$zone, and the $\mathrm{HCO}_{3}{ }^{-}-\mathrm{Na}^{+}$zone has the least gas content. According to the calculation of the Lanchester equation, the gas content of original coal seams in different zones has no significant difference. Therefore, it can be deduced that $\mathrm{Cl}^{-}-\mathrm{Na}^{+}$and $\mathrm{HCO}_{3}{ }^{-}-\mathrm{Cl}^{-}-\mathrm{Na}^{+}$zones are more favorable for $\mathrm{CBM}$ preservation.

\section{Existing Problems and Development Trends}

6.1. Existing Problems. By reviewing the literature in China and other counties, we can find that predecessors have already made significant progress in studying the mechanisms for controlling the enrichment and high yield of CBM from the aspects of coalbed hydrodynamics, coalbed hydrogeochemistry, and hydrogeological conditions. All the research achievements provide solid theoretical bases and practices for selecting the CBM enrichment area and effectively extracting CBM. However, there are still some existing problems that need to be discussed and further studied:

(1) The distribution and migration of coalbed water determine the enrichment and dissipation of CBM. Due to the complexity of geological structures, the difference in reservoir permeability, and the interaction between water and rock, more finely and threedimensional hydrogeological units are needed to make the CBM exploitation more economically beneficial. However, the current distribution rule of coalbed water is only at the stage of qualitative description, and it is urgent to establish a quantitative method to evaluate the heterogeneous distribution of coalbed water in both the longitudinal and lateral directions

(2) If the selection of favorable CBM zones and sweet spots involves hydrogeological conditions, hydrodynamic conditions are considered to a large extent. However, hydrogeochemistry, especially the isotope characteristics of coalbed water, is less considered. In addition, most of the previous studies mainly focus on the enrichment of CBM. Therefore, it is urgent to establish a comprehensive system to evaluate CBM enrichment and high production based on hydrogeological indicators

(3) The studies on the relationships among hydrodynamic conditions, hydrogeochemical characteristics, and the extraction efficiency of CBM wells are not enough. Various hydrodynamic models based on different hydrodynamic fields and dynamic changes of hydrochemistry are needed to guide highly efficient CBM extraction from CBM wells

\subsection{Development Trends}


6.2.1. Transform from Qualitative Evaluation to Quantitative Evaluation. Due to the differences in the hydrogeological conditions of groundwater, most of the predecessors defined boundaries of coalbed water distribution and divided the hydrogeological zones based on conditions such as the geomorphology, geological structure, and surface water system. However, the gas production of CBM wells in the same hydrogeological zone varies greatly. The reason is that the coalbed water has a strong vertical and horizontal heterogeneity in hydrogeological units. Therefore, it is necessary to establish a quantitative method to evaluate the heterogeneous distribution of coalbed water vertically and horizontally to accurately describe the heterogeneous distribution characteristics of hydrogeological units.

6.2.2. Transform from a Single Evaluation Standard to Multiple Evaluation Standards. The relationship between CBM enrichment and high yields shows that the area with high-yield CBM must be located at the CBM enrichment area. The coal seam water content, hydrodynamic zoning, and different hydrochemical conditions that are summarized by the predecessors obviously have controlling effects on CBM enrichment, especially on the coalbed gas content. However, the standard for evaluating the enrichment is more of a singular indicator. It is urgent to transform the singular way to evaluate CBM enrichment (gas content) to multiple ways to evaluate CBM enrichment (gas content and water content) and high production (gas production and water production) and establish an evaluation system with multiple evaluation indicators including the dynamic zones, flow intensity, water ion characterization, and water isotope.

6.2.3. Transform from Static Evaluation to Dynamic Evaluation. The hydrogeological conditions underground are accompanied by the production of CBM wells, and they are in a process of dynamic change. The content of coalbed water, hydrodynamic conditions, and hydrochemical characteristics will change with the production process of CBM. Therefore, analyzing static data to find the CBM controlling mechanism cannot meet the requirements of efficient development of CBM. On the basis of quantitatively characterizing the CBM controlling parameters of coalbed water, it is urgent to analyze the changing rules of hydrogeological parameters in the CBM production process and transform the static evaluation on the gas controlling mechanism of hydrogeological conditions to dynamic evaluation.

6.2.4. Transform Theoretical Studies to Practices Guided by Theoretical Results. The theoretical research of CBM in China starts in the 1970s and 1980s. Many theoretical breakthroughs and innovations have been made around the gas controlling effects of hydrogeological conditions. However, the hydrogeological conditions of coal seams in the CBM basin in China are of great variety. The aquifers are heterogeneously distributed. The relationships between hydrogeology and geological structures are complex. The research results are not closely related to the actual CBM extraction and production. Therefore, it is urgent to combine theoreti- cal research studies with field practices to deepen the research studies on the gas controlling mechanism of hydrogeology, to construct a comprehensive hydrogeological evaluation system and a customized and efficient drainage system that serve the exploration and development of CBM and guide the selection and efficient development of CBM enrichment areas and high-yield zones.

\section{Conclusion}

(1) From the perspective of hydrogeology, this paper summarizes the fruitful research results achieved by domestic and foreign researchers on the gas controlling effect of hydrogeology under similar structural and deposition conditions in recent years. Among them, the water conditions suitable for biogenic gas formation are identified; the division of hydrodynamic zones and its index are summarized; the response mechanism of water geochemical characteristics to CBM is analyzed; and the high production model of CBM based on different water production characteristics is established

(2) According to the research progress and existing problems, this paper proposes the following trends about research on the controlling mechanism of hydrogeological conditions: transform from qualitative evaluation to quantitative evaluation, from a singular evaluation standard to multiple evaluation standards, from static evaluation to dynamic evaluation, and from pure theoretical research to practices under theoretical guidance

\section{Data Availability}

The data that support the findings and conclusions of this study are available on request from the corresponding author, Wang Dangliang (wangdangliang@cumt.edu.cn). The data are not publicly available due to the restrictions from the Natural Science Foundation of China (No. 41872179).

\section{Conflicts of Interest}

The authors declare that they have no conflicts of interest.

\section{Acknowledgments}

Funding support from the National Natural Science Foundation of China (41872179) and the open research fund program of State Key Laboratory of Coal and CBM Co-ming (2019KF05) are acknowledged.

\section{References}

[1] Y. Bao, D. Li, and Y. Ju, "Constraints of biomethane generation yield and carbon isotope fractionation effect in the pathway of acetotrophic with different coal-rank coals," Fuel, vol. 305, article 121493, 2021. 
[2] Y. Bao, W. Wang, D. Ma et al., "Gas origin and constraint of $\delta^{13} \mathrm{C}\left(\mathrm{CH}_{4}\right)$ distribution in the Dafosi mine field in the southern margin of the Ordos Basin, China," Energy and Fuels, vol. 34, no. 11, pp. 14065-14073, 2020.

[3] S. Yan, L. Shaobo, Z. Mengjun et al., "Boundary types of coalbed methane reservoirs, main controlling factors for accumulation and prediction of enriched areas," Natural Gas Industry, vol. 29, no. 10, pp. 5-9, 2009.

[4] B. Wang, F. Sun, D. Tang, Y. Zhao, Z. Song, and Y. Tao, "Hydrological control rule on coalbed methane enrichment and high yield in FZ Block of Qinshui Basin," Fuel, vol. 140, pp. 568-577, 2015.

[5] Y. Bao, C. An, C. Wang, C. Guo, and W. Wang, "Hydrogeochemical characteristics and water-rock interactions of coalbed- produced water derived from the Dafosi biogenic gas field in the southern margin of Ordos basin, China," Geofluids, vol. 2021, Article ID 5972497, 13 pages, 2021.

[6] C. T. Rightmire, G. E. Eddy, and J. N. Kirr, Coalbed Methane Resources of the United States: AAPG Studies in Geology Series 17, The American Association of Petroleum Geologists, Tulsa, Oklahoma, 1984.

[7] B. E. Law and D. D. Rice, Hydrocarbons from Coal: $A A P G$ Studies in Geology Series 38, The American Association of Petroleum Geologists, Tulsa, Oklahoma, 1993.

[8] A. R. Scott, W. R. Kaiser, and W. B. Ayers, "Thermogenic and secondary biogenic gases, San Juan basin, Colorado and New Mexico-implications for coalbed gas producibility," $A A P G$ Bulletin, vol. 78, no. 8, pp. 1186-1209, 1994.

[9] D. Jinxing and P. Xigu, China Natural Gas Geology, Volume 1, Petroleum Industry Press, 1992.

[10] G. Deshi, "Living conditions of methanogens and biogas," Natural Gas Industry, vol. 10, no. 5, pp. 13-19, 1990.

[11] W. Bo, C. Haiyan, Z. Guiqiang et al., "Study on geological characteristics and gas control differences of high and low coal rank CBM reservoirs," Acta Geologica Sinica, vol. 10, pp. 1396-1401, 2008.

[12] S. Xianbo, X. Ying, W. Yu, and D.-P. Xia, "Effects of salinity and $\mathrm{pH}$ on biomethane production in low rank coal seams," Journal of China Coal Society, vol. 36, no. 8, pp. 1302-1306, 2011.

[13] M. P. Bryant, "Microbial methane production-theoretical aspects2," Journal of Animal Science, vol. 48, no. 1, pp. 193201, 1979.

[14] W. Bo, "Coalbed methane enrichment and high-production rule \& prospective area prediction in Qinshui Basin," China University of Mining and Technology, 2013.

[15] L. Benliang, W. Mingming, W. Guoqi et al., "Study on biogas migration and accumulation in Sanhu area of Qaidam Basin," Geological Review, vol. 1, pp. 93-100, 2003.

[16] L. Zhijun, L. Xinning, L. Hui et al., "Effect of hydrogeological conditions on low-rank coalbed methane in Tuha and Santanghu basins," Xinjiang Petroleum Geology, vol. 34, no. 2, pp. 158-161, 2013.

[17] Y. C. Wei, Q. Zhang, A. M. Wang, H. K. Ren, Y. Yuan, and D. Y. Cao, "The influence of the salinity of groundwater in coal measures on low rank coalbed methane in the south margin of Junggar basin," Coal Geology \& Exploration, vol. 44, no. 1, pp. 31-37, 2016.

[18] W. Tao, D. Ze, H. Haiyan et al., "Study on characteristics comparison of low rank coal coalbed methane reservoirs at home and abroad," Coal Science and Technology, vol. 47, no. 9, pp. 41-50, 2019.
[19] L. Zhijian, "Analysis on the mechanism and characteristics of coal gas hydrothermal metamorphism," Coal Geology \& Exploration, vol. 5, pp. 34-36, 1988.

[20] Z. Ningning and R. Deyi, "Changes of the carboniferous coalbearing rock series in Henan under the coal thermal metamorphism-a preliminary discussion on the influence of groundwater hydrothermal on coal metamorphism," Geological Review, vol. 2, pp. 130-139, 1990.

[21] Y. Jianping, W. Qiang, and W. Zihe, "Controlled characteristics of hydrogeological conditions on the coalbed methane migration and accumulation," Journal of China Coal Society, vol. 5, pp. 459-462, 2001.

[22] W. Bo, "Study on contrast of reservoir character and physical simulation experiment of high and low rank coalbed methane," China University of Mining and Technology, 2006.

[23] S. Yan, M. Xingzhi, L. Shaobo, J. Lin, H. Feng, and Q. Yi, "Gas accumulation conditions and key exploration \& development technologies in Qinshui coalbed methane field," Acta Petrolei Sinica, vol. 40, no. 5, pp. 621-634, 2019.

[24] T. Chong, T. Dazhen, Z. Zhijun, T. Shu, C. Xiaozhi, and S. Conglei, "Hydrogeological characteristics and their control on coalbed methane in Binchang mining area," Coal Geology \& Exploration, vol. 40, no. 1, pp. 43-46, 2012.

[25] J. Li, B. Wang, L. Shao et al., "Hydrogeological zoning and its gas-controlling mechanism: a case study of Baode block, eastern Ordos gas field," Journal of China University of Mining and Technology, vol. 46, no. 4, pp. 869-876, 2017.

[26] S. Yan, L. Shao-Bo, Z. Meng-Jun et al., "Coalbed gas reservoirs: boundary types, main controll ing factors of gas pooling, and forecast of gas-rich areas," Natural Gas Industry, vol. 29, no. 10, pp. 5-9, 2009.

[27] X. H. Fu, Y. Qin, W. F. Wang, and S. H. Jiao, "Hydrogeological controlled properties of coal bed gas in central-southern Qinshui Basin,” Coal Geology of China, vol. 1, pp. 31-34, 2001.

[28] Q. Rongfang, C. Daiyong, W. Anmin et al., "CBM reservoirforming model of Zhuozishan mining area in western margin of Ordos basin," Coal Geology \& Exploration, vol. 46, no. 3, pp. 54-58, 2018.

[29] Z. Yaru, S. Beilei, Z. Fangui et al., "Hydrogeological characteristics of CBM reservoirs and their controlling effects in Gujiao Mining Area, Xishan Coalfield," Journal of China Coal Society, vol. 43, no. 3, pp. 759-769, 2018.

[30] L. Zeng, X. G. Sun, S. H. Cui, and J. Y. Sui, “Controlling effects of structural-hydrogeological conditions on coalbed methane accumulation in Xishan Coalfield," Coal Science and Technology, vol. 47, no. 9, pp. 80-88, 2019.

[31] Y. C. Wei, X. X. Xiang, A. M. Wang, Q. Zhang, and D. Y. Cao, "Influence of water with different salinity on the adsorption performance of coal reservoir," Journal of China Coal Society, vol. 44, no. 9, pp. 2833-2839, 2019.

[32] S. Zhang, S. Tang, Z. Li, L. Qiao, and C. Men, "The hydrochemical characteristics and ion changes of the coproduced water: taking Shizhuangnan block, south of the Qinshui basin as an example," Journal of China University of Mining and Technology, vol. 44, no. 2, pp. 292-299, 2015.

[33] X. Zhanjie, "Study on isotopic geochemistry and origins of coalbed methane in the northern Qinshui Basin," China University of Mining and Technology Beijing, 2017.

[34] L. Chao, F. Guorui, and Z. Fangui, "Origin and geochemical characteristics of coalbed methane in abandonedcoal mines, 
Panzhuang block, southern Qinshui basin," Coal Geology \& Exploration, vol. 47, no. 6, pp. 67-72, 2019.

[35] L. Guangjing, "Analysis of geochemistry characteristics of water from coalbed methane wells in Shizhuang south block," Coal Technology, vol. 38, no. 1, pp. 60-62, 2019.

[36] J. C. McIntosh, L. M. Walter, and A. M. Martini, "Pleistocene recharge to mid-continent basins: effects on salinity structure andmicrobial gas generation," Geochimica et Cosmochimica Acta, vol. 66, pp. 1681-1700, 2002.

[37] S. D. Golding, C. J. Borehamb, and J. S. Esterle, "Stable isotope geochemistry of coal bed and shale gas and related production waters: a review," International Journal of Coal Geology, vol. 120, pp. 24-40, 2013.

[38] S. B. Wang, S. H. Tang, Y. Mo, Z. C. Li, and S. H. Zhang, "The hydrogen and oxygen isotope characteristics of drainage water from Taiyuan coal reservoir," Journal of China Coal Society, vol. 38, no. 3, pp. 448-454, 2013.

[39] E. C. Kinnon, S. D. Golding, C. J. Boreham, K. A. Baublys, and J. S. Esterle, "Stable isotope and water quality analysis of coal bed methane production waters and gases from the Bowen Basin, Australia," International Journal of Coal Geology, vol. 82, no. 3-4, pp. 219-231, 2010.

[40] C. Wu, Z. Yang, Y. Qin, J. Chen, Z. Zhang, and K. Luo, "Geochemical comparison and its geological significance of CBM produced water in the Songhe and Zhijin blocks," Journal of China Coal Society, vol. 43, no. 4, pp. 1058-1064, 2018.

[41] M. Fuyuan, "Theories and practice of CBM gas-water moving," China Coalbed Methane, vol. 13, no. 5, pp. 15-17, 2016.

[42] S. Fenjin, B. Wang, L. Mengxi et al., "Major geological factors controlling the enrichment and high yield of coalbed methane in the southern Qinshui Basin," Acta Petrologica Sinica, vol. 35, no. 6, pp. 1070-1079, 2014.

[43] B. Wang, Y. Hongxing, H. Wang et al., "Favorable and major geological controlling factors for coalbed methane accumulation and high production in the Chengzhuang Block, Qinshui Baisn,” Oil \& Gas Geology, vol. 39, no. 2, pp. 366-372, 2018.

[44] L. Jian, C. Yanqian, X. Xianyue et al., "Hydrochemistry field characteristic of 11\# coal seam in Hancheng CBM field and its controlling effect on CBM," Journal of China Coal Society, vol. 23, no. 3, pp. 74-80, 2018. 